\title{
Mapping It Out: A Novel Signaling Pathway Linking A $\beta$-PrPc-Fyn Complex to Cognitive Impairment in Alzheimer's Disease
}

\author{
Yiling Wang1 ${ }^{*}$, Lei Xue ${ }^{2^{*}}$ \\ ${ }^{1}$ Department of Neuroscience, Duke University, Durham, USA \\ ${ }^{2}$ Shanghai Key Laboratory of Signaling and Disease Research, School of Life Science, Shanghai, China \\ Email: 'yiling.wang@duke.edu, ${ }^{*}$ lei.xue@tongji.edu.cn
}

Received 5 November 2013; revised 14 December 2013; accepted 21 December 2013

Copyright (C) 2014 by authors and Scientific Research Publishing Inc.

This work is licensed under the Creative Commons Attribution International License (CC BY). http://creativecommons.org/licenses/by/4.0/ (c) (i) open Access

\begin{abstract}
Understanding the signaling cascade that leads to the rapid memory and cognitive breakdown in Alzheimer's disease is the key to finding a potential treatment method for the disease. Recently, Larson et al. connect the roles of major proteins implicated in the disease progression and propose targeting of cellular prion protein ( $\mathrm{PrPc}$ ) as a way of someday rescuing synaptic plasticity in humans with Alzheimer's, as it has been done on mice.
\end{abstract}

\section{Keywords}

\section{Alzheimer's; PrPc; A $\beta$; Fyn; Tau; Microtubule}

\section{Introduction}

Alzheimer's disease (AD), an often times-fatal form of dementia, is among the most prevalent neurodegenerative disorders alongside Parkinson's disease and Amyotrophic Lateral Sclerosis. Two of the most prominent characteristics that define Alzheimer's disease are amyloid plaques, which are solid deposits of beta-amyloid $(\mathrm{A} \beta)$ protein, and neurofibrillary tangles, comprised of insoluble aggregates of tau protein along with collapsed microtubules. For the past few decades, many have sought to understand the biological mechanisms underlying Alzheimer's disease, and although much research has gone into deciphering the roles of the key players at work, up until recently, a detailed molecular pathway leading to Alzheimer's disease had not yet been mapped out.

Some of these key players in $\mathrm{AD}$ include $\mathrm{A} \beta$ oligomers, cellular prion protein $\left(\mathrm{PrP}^{\mathrm{C}}\right)$, tau protein, and Fyn kinase. Working in conjunction with cellular prion protein $\left(\operatorname{PrP}^{\mathrm{c}}\right), \mathrm{A} \beta$ dimmers are largely responsible for inhibit-

${ }^{*}$ Corresponding authors.

How to cite this paper: Wang, Y.L. and Xue, L. (2014) Mapping It Out: A Novel Signaling Pathway Linking AB-PrP ${ }^{\mathrm{C}}$-Fyn Complex to Cognitive Impairment in Alzheimer's Disease. Advances in Alzheimer's Disease, 3, 20-23.

http://dx.doi.org/10.4236/aad.2014.31003 
ing long-term potentiation (LTP) and inducing dendritic spine loss in hippocampal neurons [1], thus causing synaptic plasticity impairment in AD patients [2]. In other AD studies, hyperphosphorylation of tau (a microtubule-associated protein) caused tau mislocalization in dendritic spines, which disrupts synaptic plasticity and cognitive function [3]. Furthermore, cognitive impairment is not only associated with heightened levels of phosphorylated tau, but it is also linked to overexpression of the protein Fyn [4], a postsynaptic protein kinase implicated in the integrin signaling pathway [5]. Therefore, evidence from previous studies suggests that $\mathrm{A} \beta$, $\operatorname{PrP}^{\mathrm{C}}$, tau, and Fyn somehow all contribute to the synaptic impairment and cognitive decline in AD patients. However, the link between the $\mathrm{A} \beta-\mathrm{PrP}^{\mathrm{c}}$-Fyn complex and tau hyperphosphorylation and how it leads to dementia in $\mathrm{AD}$ remains unclear.

\section{Role of PrPc-Dimeric A $\beta$ Signaling}

A primary goal of this paper by Larson et al. is to elucidate the molecular mechanism (Figure 1) by which oli gomeric $\mathrm{A} \beta$, coupled with $\operatorname{Pr}^{\mathrm{c}}$ receptor, phosphorylates the tyrosine kinase Fyn and produces neurofibrillary tangles in $\mathrm{AD}$ [5]. Through confocal immunofluorescence, Larson et al. observed that colocalization of $\operatorname{PrP}^{\mathrm{C}}$ and $\mathrm{A} \beta$ occurred predominantly on synaptic sites, providing evidence that $\operatorname{PrP}^{\mathrm{C}}$ serves as a membrane receptor for

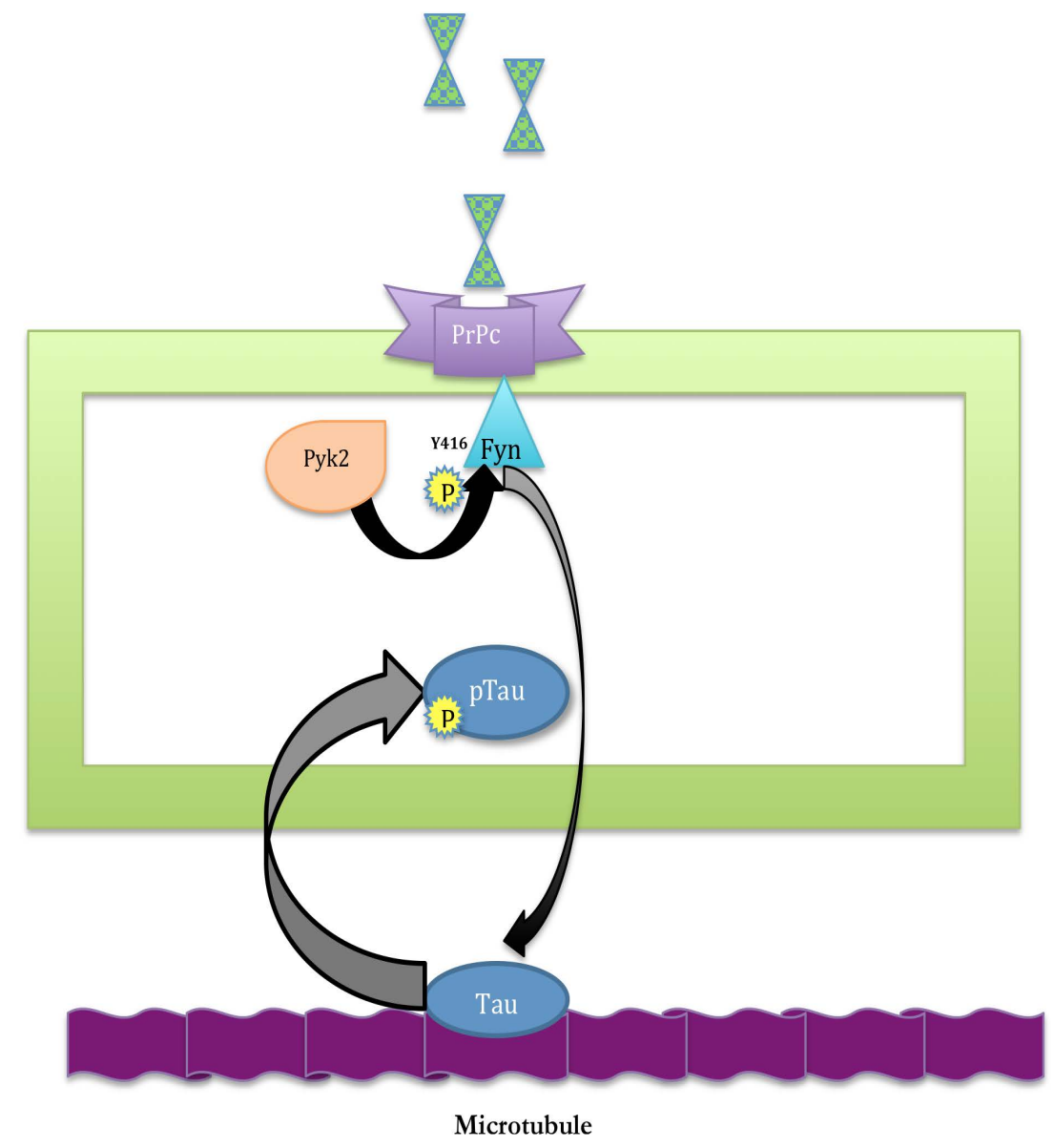

Figure 1. A schematic of the signaling cascade described by Larson et al. (2012), starting with $\mathrm{A} \beta$ dimer- PrPc binding to the disruption of tau function. (From top to bottom): (I) Endogenous $\mathrm{A} \beta$ dimers bind to $\operatorname{PrP}^{\mathrm{C}}$ receptors on cell surface; (II) Once $\mathrm{A} \beta$ binds $\operatorname{PrP}^{\mathrm{c}}$, a signaling cascade is triggered in which Pyk2 (an integrin subunit) phosphorylates Fyn at the Y416 site (a tyrosine protein kinase to which $\operatorname{PrP}^{\mathrm{c}}$ is coupled) and activates Fyn; (III) Phosphorylated Fyn moves to the dendritic spine where microtubules are mediated by the protein tau; (IV) Fyn acts on tau to hyperphosphorylate it, leading to tau dysfunction, microtubule destabilization, and impairment of synaptic plasticity. 
the $\mathrm{A} \beta$ ligand (Figure $1(\mathrm{I})$ ). Ultimately, Larson et al. characterize a signaling cascade in $\mathrm{AD}$, through which dimeric $\mathrm{A} \beta$ acts as a ligand for the $\operatorname{PrP}^{\mathrm{c}}$ receptor and activates intracellular Fyn through phosphorylation (Figure 1(II)). Fyn activation in turn hyperphosphorylates and mislocalizes tau protein in the dendritic spines, leading to destabilized microtubules, which produce neurofibrillary tangles and the cognitive impairment characteristic of AD patients (Figures 1(III) and (IV)). The authors found that AD brain tissue contained greater levels of cellular prion protein $\left(\mathrm{PrP}^{\mathrm{c}}\right)$ expression, which was positively correlated with Fyn phosphorylation. These observations support previous studies pointing to Fyn's role in mediating cognitive defects associated with AD [5]. But here, Larson et al. draws a novel connection between $\operatorname{PrP}^{\mathrm{c}}$ and Fyn, suggesting that their interaction in conjunction with the presence of $\mathrm{A} \beta$ oligomers may be bringing about the neurological impairments in $\mathrm{AD}$.

\section{Discussion}

However, in opposition to Larson et al.’s findings asserting the necessity of $\operatorname{PrP}^{\mathrm{c}}$ in mediating synaptic toxicity, several other studies produced results that are not consistent to this claim. Notably, in two studies done in 2010, APP-expressing transgenic mice displayed no significant difference in cognitive performance regardless of $\operatorname{PrP}^{\mathrm{C}}$ overexpression or ablation [6] [7]. These studies that failed to show synaptic impairment in AD as dependent upon $\operatorname{PrP}^{\mathrm{c}}$ overexpression [7] stand in direct opposition to Larson et al.'s findings.

Yet, in defense of Larson et al.'s conclusion, we must consider that, whereas the research conflicting with Larson et al.'s results experimented with 2-to-4-month-old Prnp transgenic mice, the age at which amyloid plaques actually begin forming in mice brains is no earlier than $10-14$ months old [5]. Since these beta-amyloid plaques found only in older mice comprise $\mathrm{A} \beta$ dimers, and since $\mathrm{A} \beta$ dimers are the only beta-amyloid species to bind $\mathrm{PrP}^{\mathrm{C}}$ receptors, only in the $\mathrm{AD}$ mice older than 10 months can we see the effect that $\operatorname{PrP}^{\mathrm{C}}$ receptor exerts on synaptic plasticity impairment once it binds dimeric $\mathrm{A} \beta$ [5]. Therefore, these studies [6] [7] failed to observe $\mathrm{PrP}^{\mathrm{C}}$ 's effects on LTP impairment as reported by Larson et al., not because $\operatorname{PrP}^{\mathrm{C}}$ is not implicated in the signaling pathway, but rather because the mice they experimented with were too young to have actually developed the $\mathrm{A} \beta$ dimers that bind $\operatorname{PrP}^{\mathrm{C}}$ to initiate the signaling cascade.

\subsection{Significance of Tau Mislocalization in Alzheimer's Disease}

The paper by Larson et al. is essentially the first to characterize the signaling cascade linking endogenous $\mathrm{A} \beta$ dimer with the mislocalization and hyperphosphorylation of tau in Alzheimer's disease [5]. It consolidates evidence from previous papers illustrating the roles that various molecules play to produce neuronal dysfunction in $\mathrm{AD}$. This paper pieces together the bits of information gathered from research over the decades so that this proposed pathway has logical flow throughout.

Previous studies have documented the consequences of $\operatorname{PrP}^{\mathrm{c}}$ and $\mathrm{A} \beta$ interaction on LTP impairment [1], reversal of synaptotoxic effects by $\mathrm{A} \beta$ due to genetic ablation of Fyn [4], and neurofibrillary tangles resulting from tau hyperphosphorylation [3]. But prior to this paper, it was unclear how these phenomena were related to produce Alzheimer's disease. Therefore, Larson et al. were the first to draw a link among these findings and prove a logical signaling cascade in which $\mathrm{A} \beta$ dimer binds to the $\operatorname{PrP}^{\mathrm{c}}$ receptor to activate Fyn, which then goes on to phosphorylate tau and cause tau missorting in the dendritic spine, and this tau mislocalization eventually leads to synaptic plasticity inhibition.

\subsection{Potential Treatment Methods Targeting PrPc-A $\beta$ Dimer Binding}

In addition, Larson et al. cites $\operatorname{PrP}^{\mathrm{c}}$ targeting as a potentially viable method for slowing down the progression of Alzheimer's disease in humans, since blocking $\operatorname{PrP}^{\mathrm{C}}-\mathrm{A} \beta$ dimer binding using the antibody 6D11 in $\mathrm{AD}$ mice resulted in the reversal of LTP impairment [5], or LTP rescue. Furthermore, the authors add that since $\operatorname{PrP}^{\mathrm{C}}$ receptors located on the cell membranes are readily accessible, targeting them as a possible treatment method is entirely feasible to do in the near future. Finally, this paper allows us to see why neurofibrillary tangles and amyloid-beta plaques appear simultaneously in $\mathrm{AD}$ brain tissue: the $\mathrm{A} \beta$ dimers that comprise plaques directly influence phoshporylated tau aggregation into neurofibrillary tangles.

\subsection{Future Directions}

To build upon the knowledge that Larson et al. have presented, future research may strive to find a safe and ef- 
fective way to block $\operatorname{PrP}^{\mathrm{c}}$ - $\mathrm{A} \beta$ dimer binding in humans so as to potentially rescue LTP in Alzheimer's patients. Furthermore, one may try to find any link between the integrin signaling cascade and the proposed pathway, both of which involve the Fyn kinase, as such knowledge may allow us to gain a broader perspective of how interconnected the various molecules and pathways are in the $\mathrm{AD}$ neuron.

\section{Acknowledgements}

This study was supported by Shanghai Committee of Science and Technology (grant No. 09DZ2260100).

\section{References}

[1] Shankar, G.M., Li, S., Mehta, T.H., Garcia-Munoz, A., Shepardson, N.E., Smith, I., Brett, F.M., Farrell, M.A., Rowan, M.J., Lemere, C.A., Regan, C.M., Walsh, D.M., Sabatini, B.L., and Selkoe, D.J. (2008) Amyloid $\beta$-Protein Dimers Isolated Directly from Alzheimer Brains Impair Synaptic Plasticity and Memory. Nature Medicine, 8, 837-842. http://dx.doi.org/10.1038/nm1782

[2] Laurén, J., Gimbel, D.A., Nygaard, H., Gilbert, J.W. and Strittmatter, S.M. (2009) Cellular Prion Protein Mediates Impairment of Synaptic Plasticity by Amyloid-Beta Oligomers. Nature, 457, 1128-1132. http://dx.doi.org/10.1038/nature07761

[3] Hoover, B.R., Reed, M.N., Su, J., Penrod, R.D., Kotilinek, L.A., Grant, M.K., Pitstick, R., Carlson, G.A., Lanier, L.M., Yuan, L.L., Ashe, K.H. and Liao, D. (2010) Tau Mislocalization to Dendritic Spines Mediates Synaptic Dysfunction Independently of Neurodegeneration. Neuron, 68, 1067-1081. http://dx.doi.org/10.1016/j.neuron.2010.11.030

[4] Roberson, E.D., Halabisky, B., Yoo, J.W., Yao, J., Chin, J., Yan, F., Wu, T., Hamto, P., Devidze, N., Yu, G.Q., Palop, J.J., Noebels, J.L. and Mucke, L. (2011) Amyloid-Beta/Fyn-Induced Synaptic, Network, and Cognitive Impairments Depend on Tau Levels in Multiple Mouse Models of Alzheimer's Disease. The Journal of Neuroscience, 31 , 700 -711. http://dx.doi.org/10.1523/JNEUROSCI.4152-10.2011

[5] Larson, M., Sherman, M.A., Amar, F., Nuvolone, M., Schneider, J.A., Bennett, D.A., Aguzzi, A. and Lesné, S.E. (2012) The Complex PrPc-Fyn Couples Human Oligomeric A $\beta$ with Pathological Tau Changes in Alzheimer's Disease. The Journal of Neuroscience, 32, 16857-16871. http://dx.doi.org/10.1523/JNEUROSCI.1858-12.2012

[6] Calella, A.M., Farinelli, M., Nuvolone, M., Mirante, O., Moos, R., Falsig, J., Mansuy, I.M. and Aguzzi, A. (2010) Prion Protein and Abeta-Related Synaptic Toxicity Impairment. EMBO Molecular Medicine, 2, 306 -314. http://dx.doi.org/10.1002/emmm.201000082

[7] Balducci, C., Beeg, M., Stravalaci, M., Bastone, A., Sclip, A., Biasini, E., Tapella, L., Colombo, L., Manzoni, C., Borsello, T., Chiesa, R., Gobbi, M., Salmona, M. and Forloni, G. (2010) Synthetic Amyloid- $\beta$ Oligomers Impair LongTerm Memory Independently of Cellular Prion Protein. Proceedings of the National Academy of Sciences, 107, 22952300. http://dx.doi.org/10.1073/pnas.0911829107 